\title{
PERENCANAAN GALERI TENUN ULOS DI PEKANBARU DENGAN PENDEKATAN ARSITEKTUR ANALOGI EKSPRESIONIS
}

\author{
Uli Widarti, Imbardi, Benny Hermawan
}

\author{
Program Studi Arsitektur, Fakultas Teknik, Universitas Lancang Kuning \\ Jl. Yos Sudarso km. 8 Rumbai, Pekanbaru, Telp. (0761) 52324 \\ Email: widartiuli@gmail,.com, Imbardi@unilak.ac.id
}

\begin{abstract}
ABSTRAK
Ulos merupakan kain khas dari Sumatera Utara, kain ini berbentuk selendang. Ulos merupakan symbol restu dan kasih sayang dan persatuan nenek moyang Suku Batak adalah manusia gunung hal ini dikarenakan kebiasaan mereka yang bercocok tanam. Ketika mereka hidup di gunung mereka harus siap dengan cuaca dingin yang setiap waktu akan menyerang. Awalnya mereka memanfaatkan matahari diisaat siang hari dan api unggun disaat malam hari, sedangkan panas tersebut sifatnya sementara sedangkan mereka membutuhkan panas yang bisa mereka dapatkan tanpa harus tergantung pada matahari dan api, lalu mereka menggunakan ulos suntuk menghangatkan tubuh mereka dari udara dingin. Seiring dengan berkembangnya aman ulos saat ini digunakan pada saat upacara adat seperti kelahiran, kematian, pernikahan, dan upacara adat lainnya. Menurut data statistic Indonesia tahu 2011 Suku Batak adallah suku 3 terbanyak yang mendiami Indonesia setelah Jawa dan Sunda hal ini menjadi alasan dirancangnya Galeri Tenun Ulos di Pekanbaru agar masyarakat Riau khususnya Pekanbaru dapat mengetahui dan memahami apa itu tenun ulos mulai dari sejarah, alat,dan proses pembuatannya. Oleh karena itu perlunya perancangan Galeri Tenun Ulos di Pekanbaru dengan menggusung tema Arsitektur Analogi Ekspresionis.
\end{abstract}

Kata Kunci: Konsep, Galeri, Tenun, Ulos, Pekanbaru

\section{ABSTRACT}

Ulos is a typical cloth from North Sumatra, this fabric is in the form of a shawl. Ulos is a symbol of blessing and affection and the ancestral union of the Batak people is mountain people this is because of their farming habits. When they live on the mountain they must be prepared with cold weather that will attack every time. At first they used the sun during the day and bonfires at night, while the heat was temporary while they needed heat they could get without having to depend on the sun and fire, then they used ulos to warm their bodies from cold air. Along with the safe development of ulos, it is currently used during traditional ceremonies such as birth, death, marriage, and other traditional ceremonies. According to Indonesian statistical data, 2011 the Batak tribe is the third most populous tribe inhabiting Indonesia after Java and Sunda. This is the reason for the Gallery of Weaving Ulos in Pekanbaru, so that Riau people, especially Pekanbaru, can understand and understand what ulos weaving starts from history, tools and processes. making it. Therefore the need to design the Gallery of Weaving Ulos in Pekanbaru by carrying out the theme of the Expressionist Analogy Architecture.

Keywords: Concept, Gallery, Weaving, Ulos, Pekanbaru

\section{PENDAHULUAN}

Menurut Kamus Besar Bahasa Indonesia(KKBI) Galeri adalah ruangan atau gedung tepat memamerkan atau karya seni dan sebagainya. Badan Perencanaan Pembangunan Daerah)
Ulos adalah kain tenun khas Sumatera Utara yang berbentuk selendang yang memiliki arti sebagai simbol restu dan kasih sayang.

Pekanbaru adalah Ibukota dan kota terbesar di Provinsi Riau. Kota ini merupakan salah satu sentra ekonomi terbesar di bagian timur Pulau Sumatera, dan termasuk sebagai kota dengan tingkat pertumbuhan, migrasi dan urbanisasi yang 
tinggi. Kota ini berawal dari sebuah pasar (pekan) yang didirikan di tepi Sungai Siak. Hari jadi kota ini ditetapkan pada tanggal 23 Juni 1784. Kota Pekanbaru tumbuh pesat dengan berkembangnya industri terutama yang berkaitan dengan minyak bumi, serta pelaksanaan otonomi daerah.

Alasan didirikan galeri tenun ulos dipekanbaru adalah menurut data statistik indonesia tahun 2011 suku batak adalah suku 3 terbanyak yang mendiami Indonesia setelah jawa dan sunda,hal ini memicu isu agar didirikannya galeri tenun ulos di pekanbaru agar masyarakat riau khususnya pekanbaru dapat mengetahui dan memahami apa itu tenun ulos mulai dari sejarah,alat pembuatannya,proses pembutannya dan jenis jenis ulos.

\section{METODE PENELITIAN}

Metode yang di gunakan adalah pengumpulan datadata yang terkait dengan perencanaan dan perancangan Galeri Tenun Ulos di Pekanbaru

\subsection{Studi Pustaka}

Mengumpulkan data dari perpustakaan berupa buku, jurnal dan karya ilmiah lainnya yang berhubungan dengan perencanaan Galeri Tenun Ulos di Pekanbaru, Arsitektur Analogi Ekspresionis,

\subsection{Studi Banding}

Melakukan peninjauan langsung ke Siantar, Rumah Tenun, Pajak Horas Kota Siantar Sumatera Utara.

\subsection{Wawancara}

Melakukan wawancara kepada pengarajin tenun ulos di Siantar

\section{HASIL DAN PEMBAHASAN}

Pekanbaru adalah ibu kota dan kota terbesar di provinsi Riau, Indonesia. Kota ini merupakan salah satu sentra ekonomi terbesar di bagian timur Pulau Sumatera, dan termasuk sebagai kota dengan tingkat pertumbuhan, migrasi dan urbanisasi yang tinggi sehingga membuat kota pekanbaeu banyak dihuni penduduk dari seluruh Indonesia salah satunya dari sumatera utara.

Pemilihan site pada lokasi Galeri Tenun Ulos di Pekanbaru adalah site yang memiliki potensi yang mendukung di Pekanbaru..

$\begin{array}{ll}\text { Kota } & \text { : Pekanbaru } \\ \text { Provinsi } & \text { : Riau } \\ \text { Batas Wilayah } & \\ \text { Utara } & : \text { Pertokoan } \\ \text { Timur } & \text { : Jl.Soekarno Hatta } \\ \text { Selatan } & : \text { Grand Suka Hotel } \\ \text { Barat } & \text { :Lahan Kosong } \\ \text { Luas Tapak } & : 10.400 \mathrm{~m}^{2}\end{array}$

\subsection{Analisis Tapak}

Lahan yang digunakan dalam perencanaan seluas $1.4 \mathrm{Ha}$ yang merupakan lahan kosong dan memiliki potensi yang menarik untuk membangun Galeri Tenun Ulos dengan memilih view matahari terbit dan mengarah jalan Soekarno Hatta, yang merupakana akses masuk ke tapak.

\section{Dimensi Tapak}

Pengambilan dimensi tapak di perkirakan Berdasarkan kebutuhan ruang dalam perencanaan, luas site adalah.

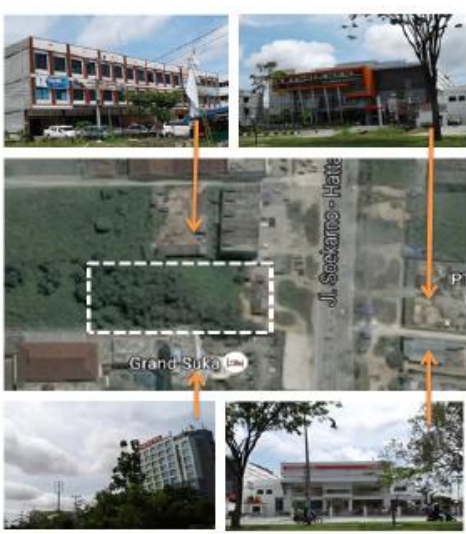

Gambar 1. Akses Menuju Lokasi (Sumber: data pribadi)

\subsection{Analisis view}

Orientasi view mengarah pada bagian timur, analisis ini mengambil rotasi matahari terbit dan jalan besar yang merupakan akses masuk kebangunan
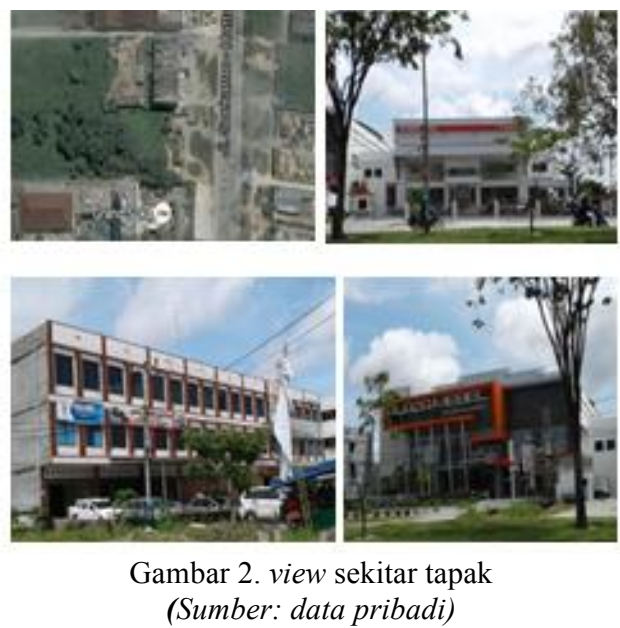

\subsection{Analisis Topografi}

Dilihat dari kondisi tanah gambut perencanaan Galeri Tenun Ulos di Pekanbaru menggunakan pondasi tiang pancang. 


\subsection{Analisis Sirkulasi}

Kondisi eksisting tapak terdapat 1 akses jalan yang merupakan jalan besar dan akses masuk kelokasi tapak Pencapaian di tempuh dengan kendaraan umum,roda 2 dan 4.

\subsection{Analisis Pencahayaan Pada Bangunan}

Pencahayaan merupakan aspek yang berpengaruh bagi aktifitas kegiatan galeri, aspek ini membahas tentang bagaimana tampilan pada suatu objek pameran. Berikut adalah 2 jenis penerapan pencahayaan pada Galeri Tenun Ulos di Pekanbaru yaitu:

a. Pencahayaan Alami

Menerapkan sistem pencahayaan pada bangunan galeri dengan menggunakan sinar matahari melalui bukaan-bukaan yang direncanakan pada bangunan.

b. Pencahayaan Buatan

Penerapan sistem pencahayaan pada bangunan dengan menggunakan sinar lampu listrik yang menyinari suatu ruangan pada galeri. Pencahayaan ini bersifat fokus sehingga dapat diterapkan sebagai penerangan pada benda objek galeri dan sebagai penegas pada konsep sirkulasi.

\subsection{Analisi Sistem Jaringan Air}

a. Sistem Jaringan Air Bersih

Air bersih pada bangunan bersumber dari Perusahaan Daerah Air Minum(PDAM) dan sumur bor sebagai sumber air bersih alternatif. Berikut adalah skema sistem jaringan air bersih pada bangunan.

b. Sistem Jaringan Air Kotor

Air kotor pada bangunan ini berupa buangan air kotor yang berasal dari urinoir, toilet, wastafel dan dari dapur yang akan disalurkan ke bak kontrol dan selanjutnya akan disalurkan pada pembuangan akhir yaitu sumur peresapan.

\subsection{Analisis Vegetasi}

Vegetasi ditentukan sebagai pendukung pada penghawaan agar lebih alami, selain untuk penghawaan vegetasi juga digunakan sebagai peredam suara yang berasal dari jalan raya

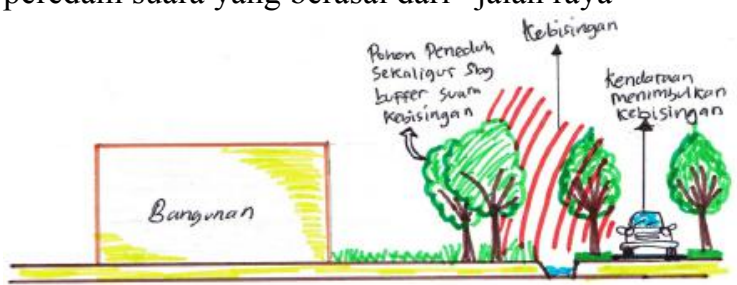

Gambar 3. Analisis vegetasi

(Sumber: Dokumentasi Pribadi)
3.8. Analisis Aktifitas dan Kebutuhan Ruang 3.2.1 Tabel Pengelola

\begin{tabular}{|c|l|l|l|}
\hline No & \multicolumn{1}{|c|}{ Pelaku } & \multicolumn{1}{|c|}{ Aktifitas } & \multicolumn{1}{|c|}{ Ruang } \\
\hline 1 & \multirow{4}{*}{ Direktur } & Datang & Parkir \\
\cline { 3 - 4 } & & Memimpin Pengelolaan & Ruang Direktur \\
\cline { 3 - 4 } & & Mengawasi Pekerjaan & Ruang Pengelola \\
\cline { 3 - 4 } & & Ishoma & Musholla, Restaurant \\
\cline { 3 - 4 } & Rapat & Ruang Rapat \\
\cline { 3 - 4 } & MCK & Toilet \\
\hline
\end{tabular}

\begin{tabular}{|c|c|c|c|}
\hline & & $\begin{array}{l}\text { Menyediakan Bahan } \\
\text { Makanan }\end{array}$ & R. food and beverage \\
\hline & & $\begin{array}{l}\text { Mengurus Segala } \\
\text { Macam Makanan Dan } \\
\text { Minuman }\end{array}$ & R. food and beverage \\
\hline & & $\begin{array}{l}\text { Memperhatikan } \\
\text { Kebutuhan Dapur }\end{array}$ & $\begin{array}{l}\text { Tempat Penyimpanan } \\
\text { Makanan }\end{array}$ \\
\hline & & Memasak & Dapur \\
\hline 5 & Food And & Menyiapkan Makanan & Pantry \\
\hline & & $\begin{array}{lr}\text { Mengurus } & \text { Layanan } \\
\text { Makanan } & \text { Dan } \\
\text { Minuman } & \end{array}$ & R. Restaurant \\
\hline & & $\begin{array}{l}\text { Mencuci Perlengkapan } \\
\text { Yang Digunakan }\end{array}$ & Ruang Cuci \\
\hline & & Rapat & R. Rapat \\
\hline & & Buang air & Toilet \\
\hline & & Isoma & R. Sholat \\
\hline
\end{tabular}

\begin{tabular}{|c|c|c|c|}
\hline \multirow[t]{6}{*}{2} & \multirow[t]{6}{*}{ Wakd Direituc } & Datang & Paschir \\
\hline & & Memimpin Pengesolase & Resag Wakd Drekna \\
\hline & & Menzanasi Pekeriasn & Ruang Pengelola \\
\hline & & Istomama & Moubollia, Restaucast \\
\hline & & Rapat & Ruang Rapat \\
\hline & & MCK & Todet \\
\hline \multirow[t]{5}{*}{3} & \multirow[t]{5}{*}{ Bekretarit } & Datang & Parsir \\
\hline & & Bekerja & Fosog Selareacist \\
\hline & & Traboma & Moschollia, Restaveraen \\
\hline & & Rapat & Reang Rapat \\
\hline & & $\operatorname{MCK}$ & Todet \\
\hline \multirow[t]{5}{*}{4} & \multirow{5}{*}{$\begin{array}{l}\text { Koof- } \\
\text { Operasional } \\
\text { den karyanan }\end{array}$} & Datang & Parar \\
\hline & & Merencanaban Kegistan & Rg Koor Operasional \\
\hline & & Istoma & MGochollia, Restaverant \\
\hline & & Rapat & Rsong Rapat \\
\hline & & MCK & Tolet \\
\hline \multirow[t]{6}{*}{5} & \multirow{6}{*}{$\begin{array}{l}\text { Roor- } \\
\text { Adminisrasi } \\
\text { Can karyanan }\end{array}$} & Datang & Parkir \\
\hline & & Mengeres Adminisrasi & $\overline{R g}_{g}$ Koos Administrasi \\
\hline & & Mengefaloasi Laporan & Resang Toags"s \\
\hline & & Itaboma & Mosholib, Restaverast \\
\hline & & Ragat & Roang Rapat \\
\hline & & MCK & Todet \\
\hline \multirow[t]{2}{*}{6} & \multirow[t]{2}{*}{$\begin{array}{l}\text { Roor- Iaventarit } \\
\text { dan karyaman }\end{array}$} & Datang & Pashir \\
\hline & & Mengocus Inventaris & Ig Koor. Iavedararit \\
\hline
\end{tabular}




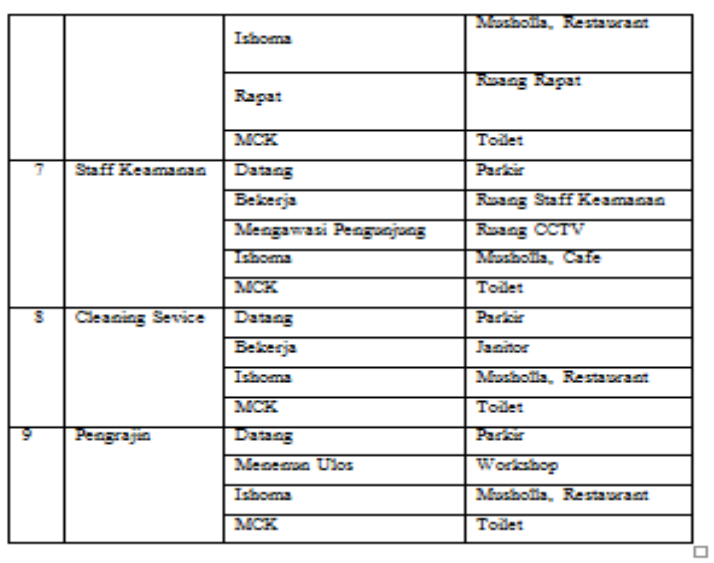

.2 .2 Tabel Pengunjung

\begin{tabular}{|c|c|c|c|}
\hline \multirow[t]{8}{*}{1} & \multirow{8}{*}{$\begin{array}{c}\text { Masyarabat, } \\
\text { Mabasions, } \\
\text { Pelajar. }\end{array}$} & Dataes & Parkin \\
\hline & & \begin{tabular}{|l} 
Melhat Pamerae \\
\end{tabular} & Rusag Pameran \\
\hline & & Menglesti Seminas & \begin{tabular}{|l|} 
Ruang Serbagzos \\
\end{tabular} \\
\hline & & Berkelling & \\
\hline & & Reireasi & Roseg Edjaiment \\
\hline & & Sholat & \begin{tabular}{|l|l} 
Mostolla \\
\end{tabular} \\
\hline & & Makan & RestavasanCafe \\
\hline & & MCK & Tollet \\
\hline
\end{tabular}

\subsection{Analisis Besaran Ruang}
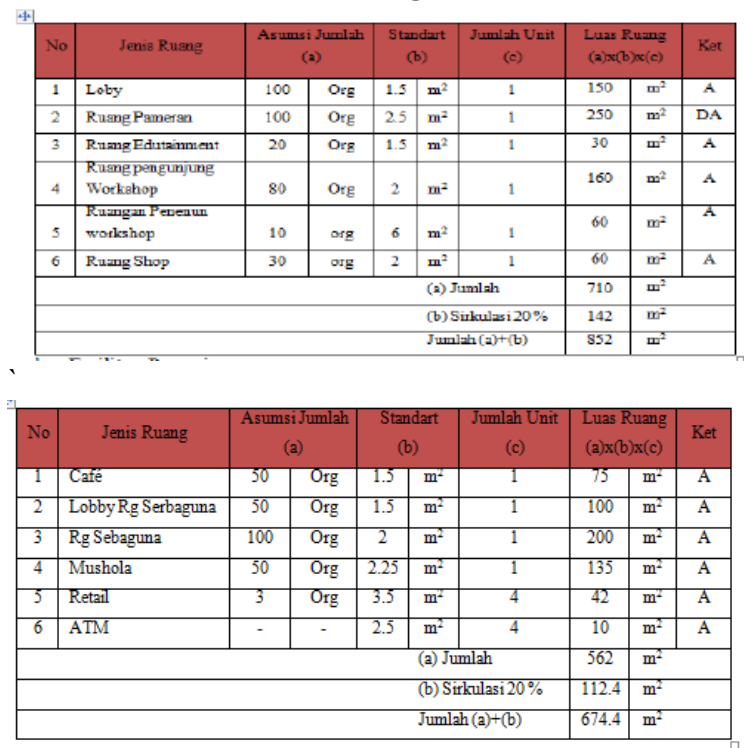

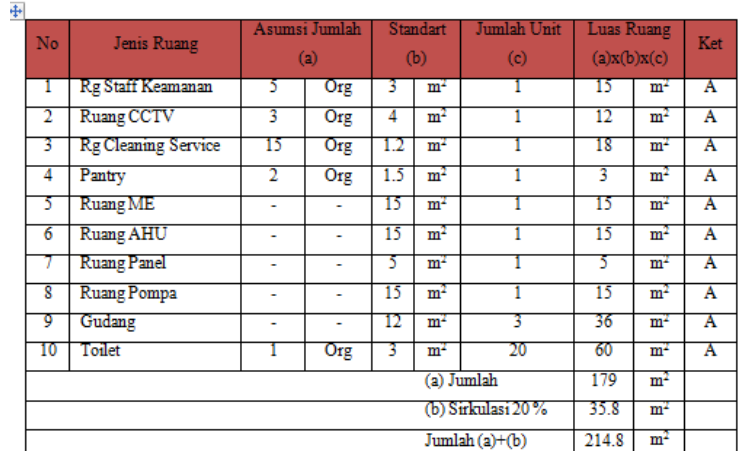

\begin{tabular}{|c|l|c|c|c|c|c|c|c|c|}
\hline \multirow{2}{*}{ No } & \multicolumn{1}{|c|}{ Jenis Ruang } & \multicolumn{2}{|c|}{$\begin{array}{c}\text { Asumsi Jumlah } \\
\text { (a) }\end{array}$} & \multicolumn{2}{c|}{$\begin{array}{c}\text { Standart } \\
\text { (b) }\end{array}$} & \multicolumn{2}{|c|}{$\begin{array}{c}\text { Jumlah Unit } \\
\text { (c) }\end{array}$} & $\begin{array}{c}\text { Luas Ruang } \\
\text { (a) } \mathrm{x}(\mathrm{b}) \mathrm{x}(\mathrm{c})\end{array}$ & Ket \\
\hline 1 & Ruang Direktur & 2 & Org & 6 & $\mathrm{~m}^{2}$ & 1 & 12 & $\mathrm{~m}^{2}$ & DA \\
\hline 2 & Ruang Selketaris & 2 & Org & 9 & $\mathrm{~m}^{2}$ & 1 & 18 & $\mathrm{~m}^{2}$ & DA \\
\hline 3 & Rg Koor Operasional & 3 & Org & 4 & $\mathrm{~m}^{2}$ & 1 & 12 & $\mathrm{~m}^{2}$ & $\mathrm{~A}$ \\
\hline 4 & Rg Koordinator Adm & 3 & Org & 4 & $\mathrm{~m}^{2}$ & 1 & 12 & $\mathrm{~m}^{2}$ & $\mathrm{~A}$ \\
\hline 5 & Rg Koor Inventaris & 3 & Org & 4 & $\mathrm{~m}^{2}$ & 1 & 12 & $\mathrm{~m}^{2}$ & $\mathrm{~A}$ \\
\hline 6 & Ruang Rapat & 15 & Org & 1.5 & $\mathrm{~m}^{2}$ & 1 & 22.5 & $\mathrm{~m}^{2}$ & DA \\
\hline 7 & Ruang Arsip & - & - & 12 & $\mathrm{~m}^{2}$ & 1 & 12 & $\mathrm{~m}^{2}$ & $\mathrm{~A}$ \\
\hline 8 & Ruang Istirahat & 2 & org & 4 & $\mathrm{~m}^{2}$ & 1 & 8 & $\mathrm{~m}^{2}$ & \\
\hline
\end{tabular}
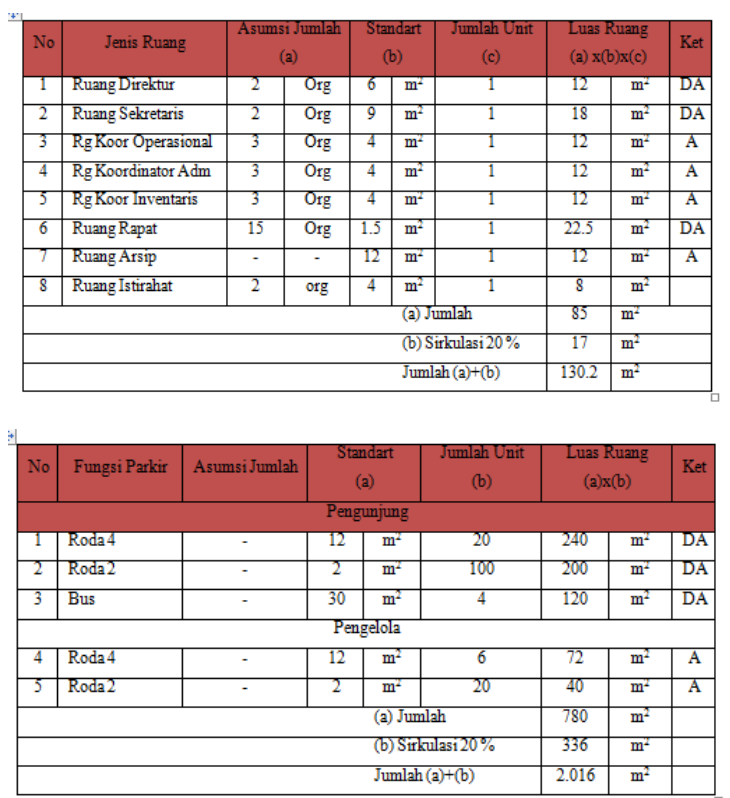

\begin{tabular}{clcc}
\hline No & Kelompok Fasilitas & \multicolumn{2}{c}{ Besaran Ruang } \\
\hline 1 & Fasilitas Utama & 852 & $\mathrm{~m}^{2}$ \\
$\mathbf{2}$ & Fasilitas Penunjang & 674.4 & $\mathrm{~m}^{2}$ \\
$\mathbf{3}$ & Fasilitas Service & 214.8 & $\mathrm{~m}^{2}$ \\
$\mathbf{4}$ & Fasilitas Pengelola & 130.2 & $\mathrm{~m}^{2}$ \\
$\mathbf{5}$ & Fasilitas Parkir & 2.016 & $\mathrm{~m}^{2}$ \\
\hline & Total Luasan & 3.911 .4 & $\mathrm{~m}^{2}$ \\
\hline
\end{tabular}


3.10 .

\section{Analisis Aspek Bangunan}

3.10.1. Analisis Bentuk Dasar Bangunan

Bentuk dasar bangunan diambil dari salah satu motif pada ulos dan diekspresikan pada bentuk bangunan.
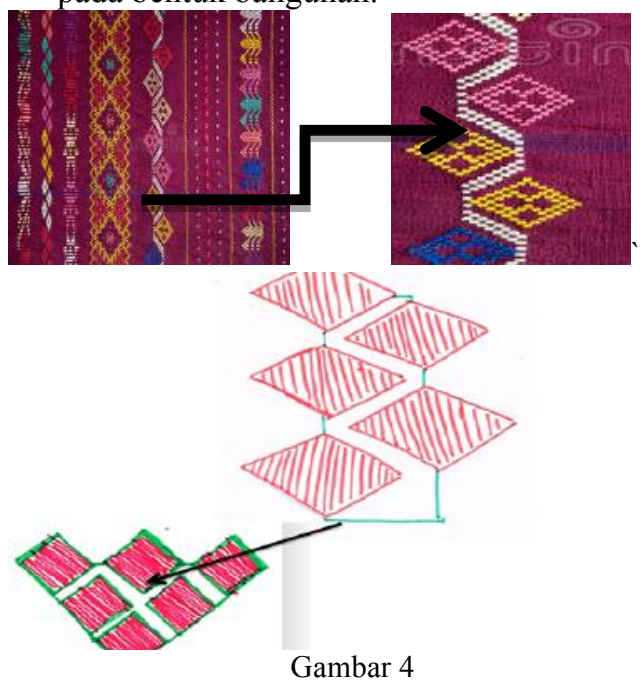

. Konsep Dasar Perancangan

(Data Skematik Tugas Akhir)

\subsection{Konsep Dasar Perancangan}

Konsep dasar perencanaan Galeri Tenun ULOS yaitu dengan pendekatan arsitektur analogi ekspresionis.

\subsection{Konsep Zoning Kawasan}

Zoning merupakan pembagian zona dalam mendesain, adapun beberapa bagian dari zoning yaitu:

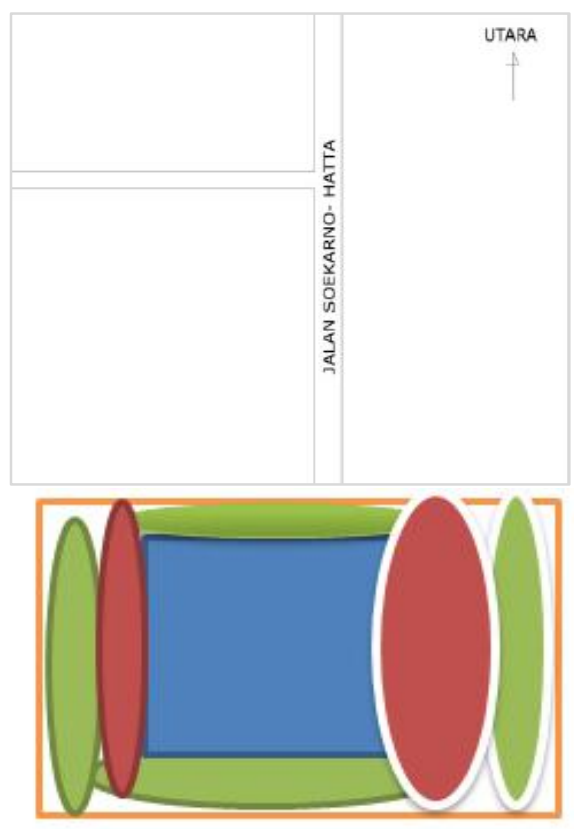

Gambar 5

. Konsep Zoning Kawasan
(Data Skematik Tugas Akhir)

Zona masa bangunan ditempatkan ditengah pada tapak, konsep ini bertujuan agar massa bangunan menjadi pusat view dari arah luar,

Zona hijau dirancang pada bagian view depan,samping kiri,samping kanan dan belakang bangunan sebagai view utama dari bangunan, di area ini akan dirancang untuk kegiatan outdor, dan open space,

Zona Parkir roda 4 dan 2 pengunjung dirancang berada di depan bangunan,sedangkan parkiran buat pengelola terletak di belakang bangunan

\subsection{Konsep Perwujudan Arsitektur Analogi Ekspresionis Terhadap Galeri Tenun Ulos}

Konsep bangunan adalah analogi ekspresionis yang dimana artinya adalah hasil ekspresi si arsitek terhadap bangunan yang dirancang. Bentuk masa bangunan mengadopsi dari salah satu motif pada kain tenun ulos yang dituangkan kedalam bentuk masa bangunan.Yang akan menggunakan umpak, jendela dan ventilasi sebagai penghawaan alami, dan juga atap limas

\subsection{Konsep Ruang Dalam}

Bentuk ruang dalam bangunan adalah meenggunakan bahan beton dan pola sirkulasi bangunan dalam adalah pola sirkulasi mengalir sehingga pengunjung galeri diharuskan mengelilingi seluruh ruangan didalam galeriI

\subsection{Konsep Ruang Luar}

Bentuk luar bbangunan adalah menggunakan bahan beton. Diluar bangunan juga menapilkan motif atau sibol bangunan sumatera utara yang berfungsi sebagai pengenal jika bangunan ini adalah galeri tenun ulos

\subsection{Hasil Perancangan}




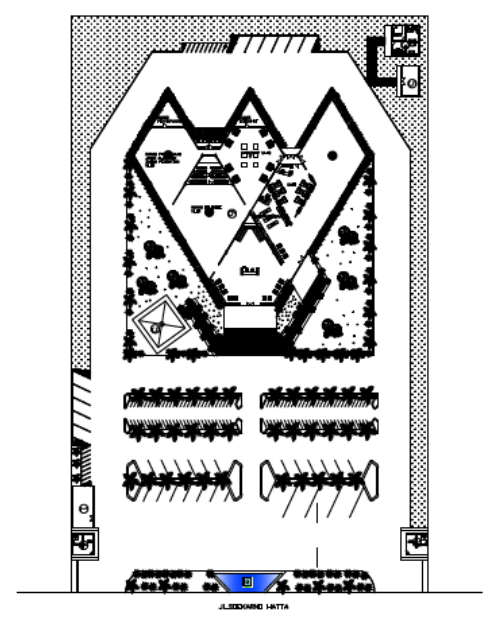

Gambar 6. Site Plan (Sumber : Dokumentasi pribadi)

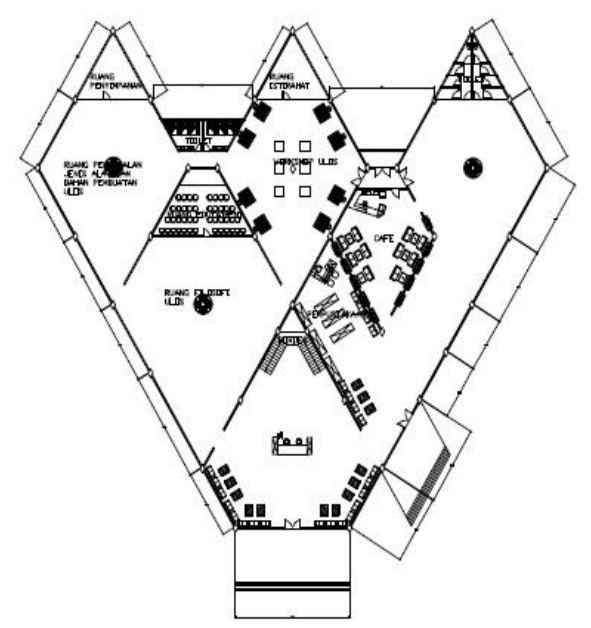

Gambar 7. Denah Lantai 1 Galeri (Sumber : Dokumentasi pribadi)

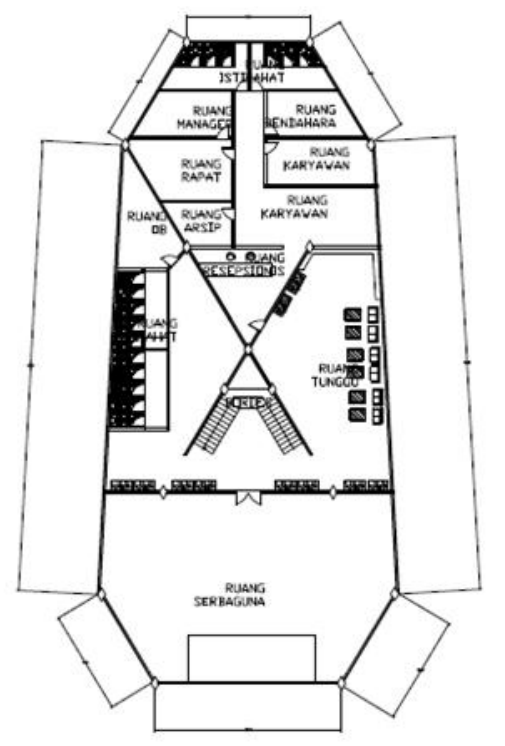

Gambar 8. Denah Lantai 2 Galeri (Sumber : Dokumentasi pribadi)

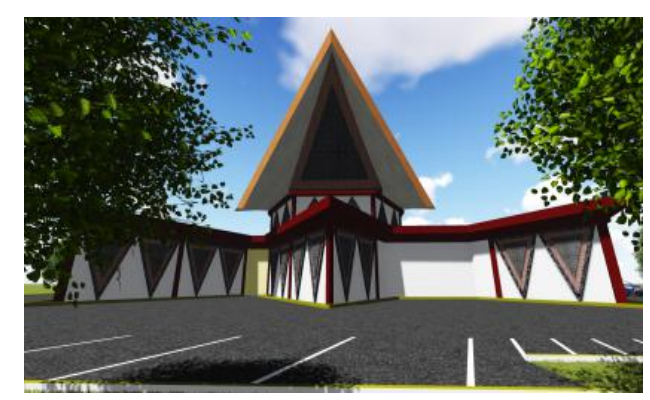

Gambar 9. Tampak Belakang (Sumber : Dokumentasi pribadi)

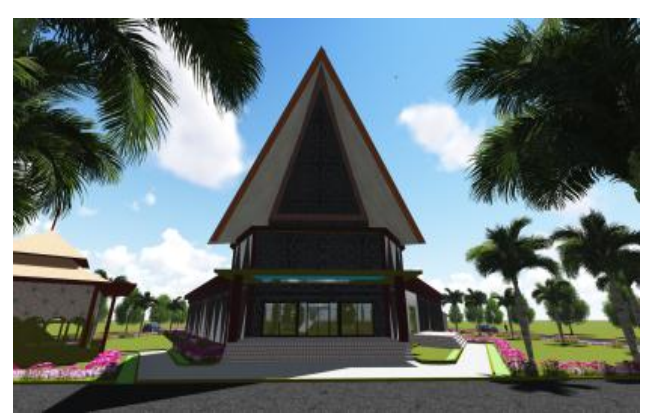

Gambar 10. Tampak Depan Galeri (Sumber : Dokumentasi pribadi)

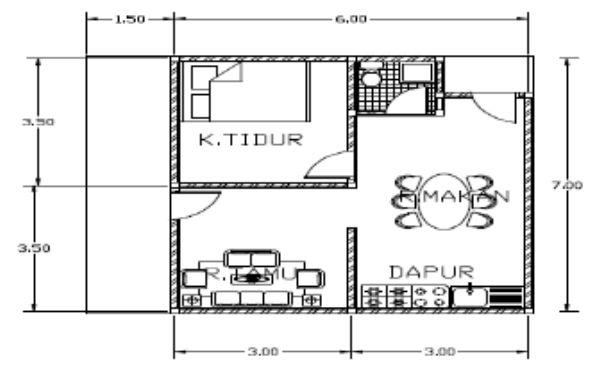

Gambar 11. Denah Rumah Penjaga

(Sumber : Dokumentasi pribadi) 


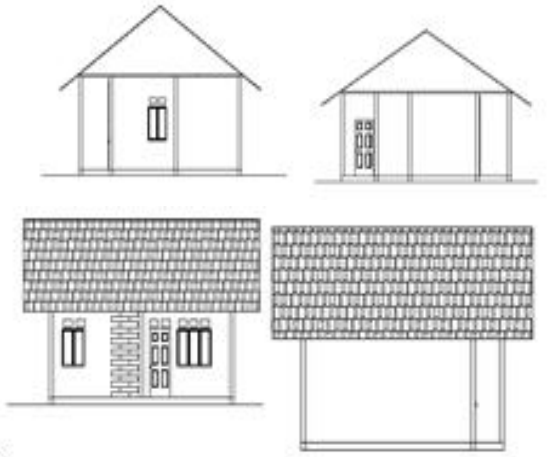

Gambar 12. Tampak Depan, Belakang, Kiri Kanan Rumah Penjaga (Sumber : Dokumentasi pribadi)

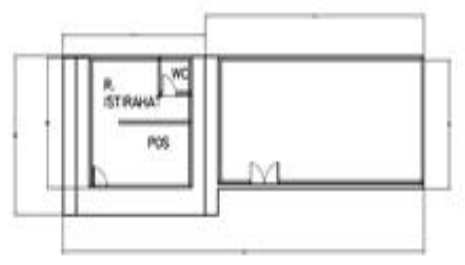

Gambar 13. Denah Pos Jaga dan ATM Center (Sumber :
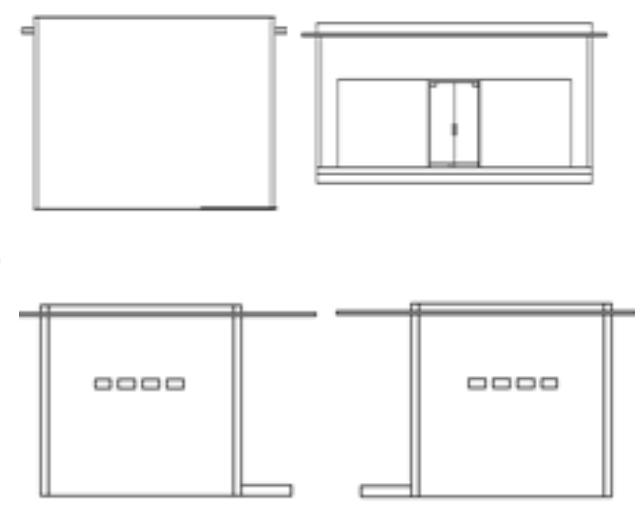

' Gambar 14. Tampak Depan, Belakang, Kanan, Kiri ATM Center
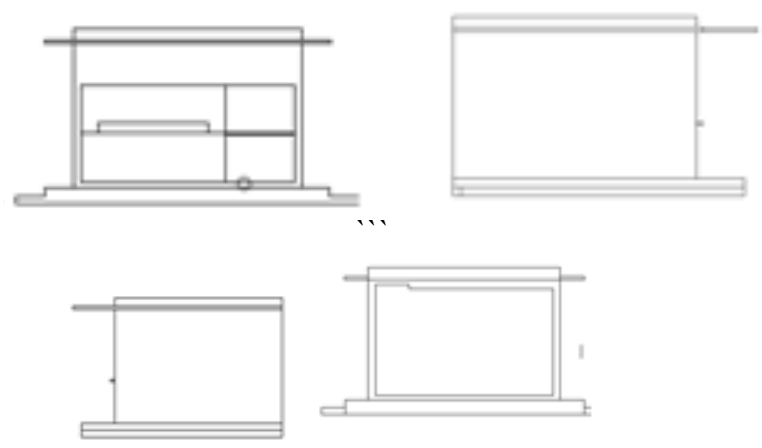

Gambar 14. Tampak Depan, Belakang, Kanan, Kiri Pos Jaga

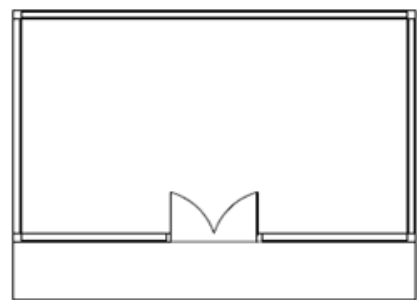

Gambar 15. Denah Ruang Genset

(Sumber : Dokumentasi pribadi)
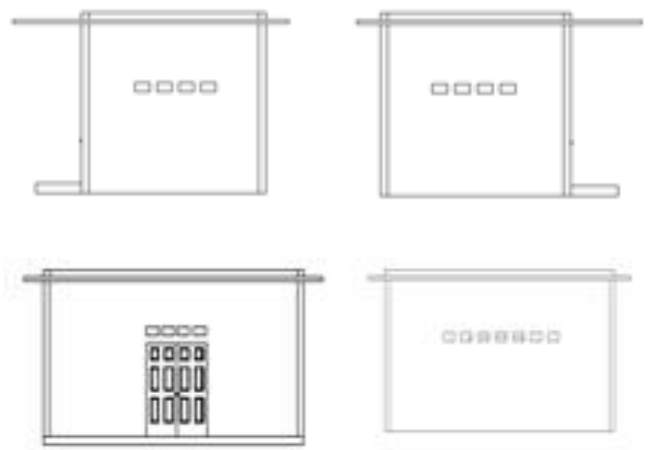

Gambar 16. TampakDepan, Belakang , Kanan, Kiri Ruang Galeri (Sumber : Dokumentasi pribadi)

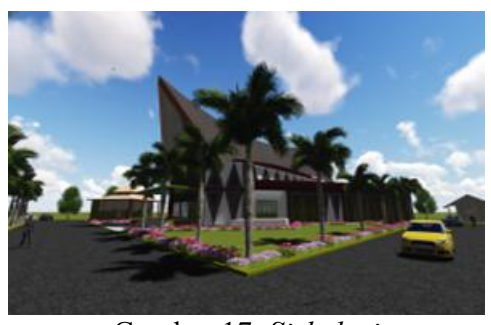

Gambar 17. Sirkulasi

(Sumber : Dokumentasi pribadi)

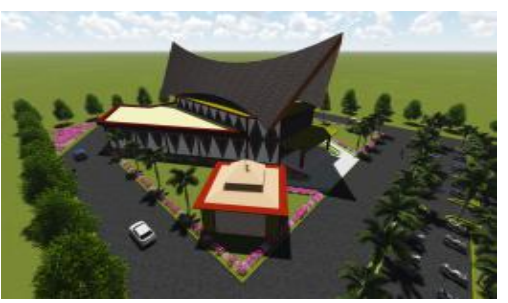

Gambar 29. Perspektif Galeri (Sumber : Dokumentasi pribadi)

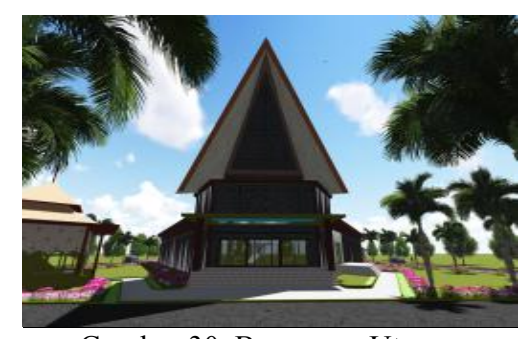

Gambar 30. Bangunan Utama (Sumber : Dokumentasi pribadi) 


\section{KESIMPULAN DAN SARAN}

Perencanaan Galeri Tenun Ulos di Pekanbaru. Pekanbaru merupakan perencanaan aktivitas yang mewadahi pameran,penjualan kain tenun ulos,dan juga sebagai tempat buat masyarakat riau khususnya pekanbaru untuk mengenal kain ulos

Perencanaan galeri ini sebagai objek wisata edukasi buat penduduk pekanbaru dan untuk meningkatkan. Ekonomi masyarakat dalam bidang perdagangan

Perencanaan galeri ini sebagai objek wisata edukasi buat penduduk pekanbaru dan untuk meningkatkan. Ekonomi masyarakat dalam bidang perdagangan

\section{DAFTAR PUSTAKA}

D.K. Ching,Francis. 2008.Arsitektur bentuk, ruang, dan tatanan.

Jurnal Sentra Kerajinan Tenun Riau Solihindra 